\title{
Ultimate Performance of Timber Connection with Normal Screws
}

\author{
Z.Zabihi \& R.Shrethta \& C.Gerber \& B.Samali \& K.Crews \\ School of Civil and Environmental Engineering, Faculty of Engineering and Information Technology, \\ University of Technology, Sydney, Australia
}

\begin{abstract}
This paper presents the results of experimental push-out tests on two different types of timber composite connections using only normal screws as the shear connecter. The push out tests were conducted based on Eurocode 5 recommendations and the load-slip responses obtained from lab tests are used to determine the stiffness of the connections at serviceability, ultimate and near collapse levels, and the performance of the connection are assessed at ultimate load. Moreover, an analytical model is derived for each type of the connection based on the experimental results and using a non linear regression, which can be implemented into non-linear FE analysis of timber beams with normal screws.
\end{abstract}

\section{INTRODUCTION}

Although the use of engineered wood products such as LVL in the floor construction has increased in Australia and New Zealand recently, several studies have highlighted the notable lack of timber used in non-residential buildings [1]. In this regard, extensive laboratory tests have been conducted on long span timber floor modules ( $6 \mathrm{~m}$ and $8 \mathrm{~m}$ clear span) at the University of Technology Sydney (UTS). In this experimental investigation, the static and dynamic behaviour of these timber floor modules were assessed under serviceability and ultimate load. The bond between flanges and the webs for all these timber modules was provided by the glue and screws. The screws used were normal type 17 wood screws, with a total length of $90 \mathrm{~mm}$, the thread length of $45 \mathrm{~mm}$ and with a diameter of $5 \mathrm{~mm}$. Their role was simply to hold the web and the flanges in place while the glue sets properly. However, the actual bond between the flanges and the webs is provided by the glue.

Although the glued and screwed bond performs fully composite under serviceability loads, at the ultimate limit state, the performance of the timber modules depends on the quality of the interfaces of the section. If a lack of adequate glue is identified between the flanges and webs, the screws bear the shear force at the interface and hence, they play a critical structural role at the ultimate load. Therefore, the behaviour of the screws when they are acting as the only load bearing part of the bond is important.
In order to assess the performance of the bond at the ultimate load, timber connections were fabricated according to the Australian Standard AS 1649 [2], using only normal screws as the shear connecter, and they were tested under push out load.

\section{EXPERIMENTAL INVESTIGATION}

\subsection{Test Specimens}

The push out test for the timber connection was followed by the experimental investigation of $6 \mathrm{~m}$ and $8 \mathrm{~m}$ full scale LVL timber beams. A total number of six serviceability (SLS) and three destructive (ULS) tests were conducted on $6 \mathrm{~m}$ and $8 \mathrm{~m} \mathrm{LVL}$ timber modules with the cross sectional dimensions shown in Figure 1 and 2.

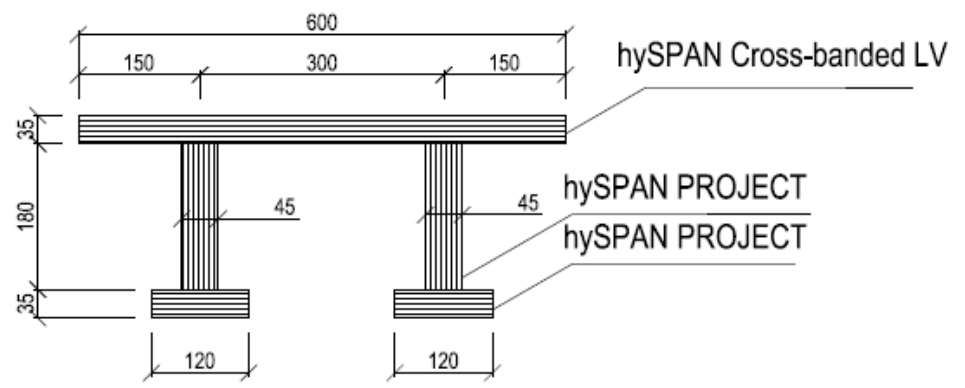

Figure 1. Dimensions for $6 \mathrm{~m}$ Span timber modulus (mm) 


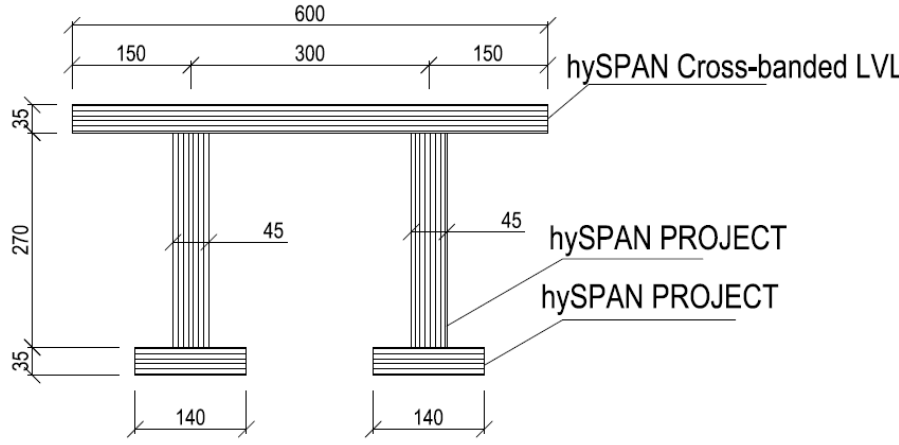

Figure 2. Dimensions for 8m Span timber modulus (mm)

As shown in the Figure 1 and 2, hySPAN crossbanded LVL and hySPAN PROJECT was used for top flange and bottom flanges, respectively. Therefore two types of connections were built to replicate the bond of top and bottom flanges with the webs. The connections were designed according to Australian Standard AS1649 [2] and Figure 3 shows the dimensions and the type of materials which were used for building connection type 1. As illustrated in Figure 3, the test specimens are $350 \mathrm{~mm}$ long and made of $90 \mathrm{~mm}$ wide and $35 \mathrm{~mm}$ deep flanges. The thickness of the web is $45 \mathrm{~mm}$, with the length of $90 \mathrm{~mm}$. The second type (connection type 2 ) is exactly similar to the first type except the fact that the hySPAN PROJECT LVL was used as the material of the flanges instead of hySpan Cross banded LVL.
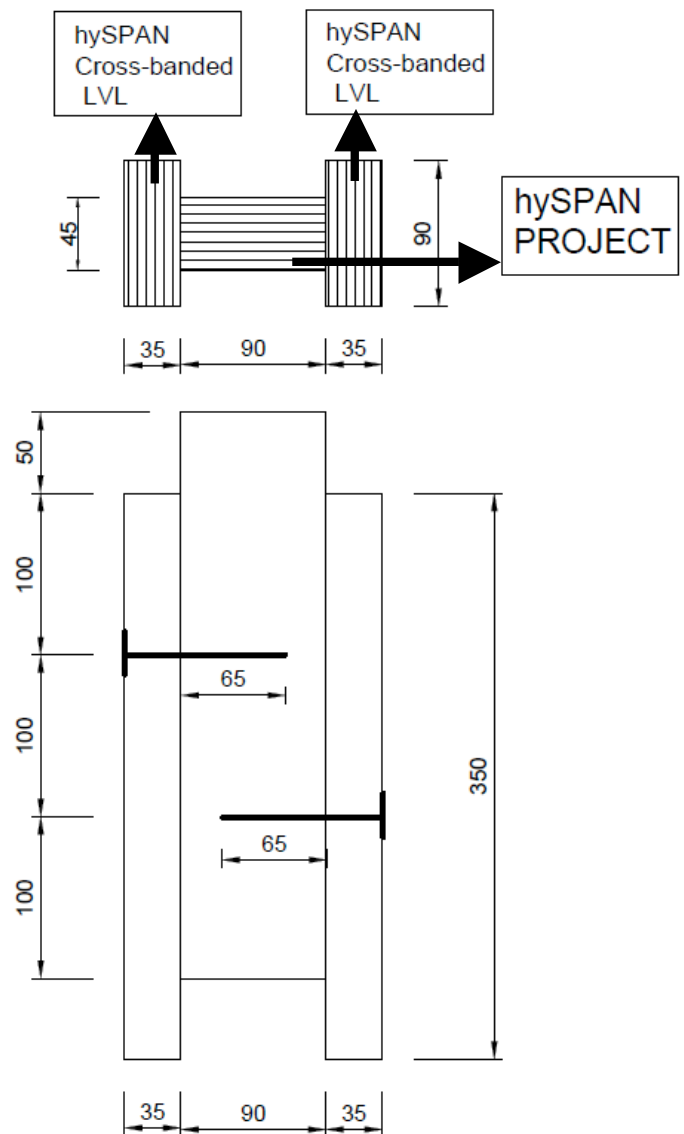

Figure 3. Dimensions of the timber connections (mm)
Figure 4 shows the dimensions of the normal screws, type 17 wood screws, used in fabricating the connection which were identical to the one used in the floor modules.

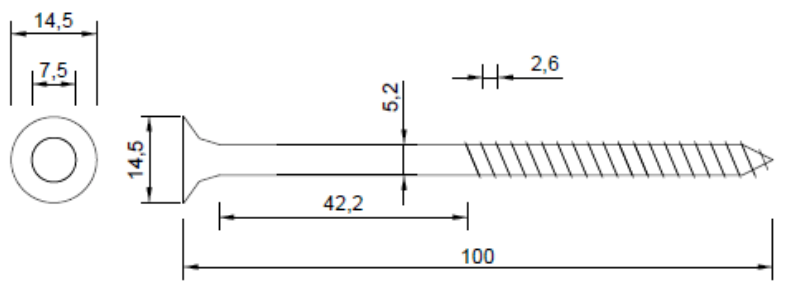

Figure 4. Dimensions of the normal screws (mm)

\subsection{Material Properties}

A number of tests were conducted on two types of LVL (hySPAN Cross-banded LVL and hySPAN PROJECT LVL), to determine their material properties. The material properties tests (including density, bending strength, the apparent modulus of elasticity (MoE), shear strength, tension and compression strength parallel to the grain) were conducted according to Australasian Standard AS/NZS4063.1:2010 [3]. However, in this paper, only the values of MoE are presented (Table 1)

To confirm the Modulus of Elasticity (MoE) of the LVL, 15 tests were conducted on hySPAN Cross-banded LVL in flat-wise fashion and 15 tests were conducted on hySPAN PROJECT LVL in both flat-wise and edge-wise directions. The results are presented in Table 1. As shown in Table 1, the coefficient of variation $(\mathrm{CoV})$ is up to of $12.3 \%$ which confirms the variable nature of timber.

Table 1. MOE of LVL

\begin{tabular}{|l|l|l|}
\hline Component Name & $\begin{array}{l}\text { MOE } \\
(\mathrm{GPa})\end{array}$ & $\mathrm{CoV}$ \\
\hline $\begin{array}{l}\text { Top Flange (hySPAN Cross-banded LVL, } \\
\text { Flat-Wise tests) }\end{array}$ & 9.6 & $10.7 \%$ \\
\hline $\begin{array}{l}\text { Webs (hySPAN PROJECT LVL, Edge- } \\
\text { Wise tests) }\end{array}$ & 13.3 & $4.6 \%$ \\
\hline $\begin{array}{l}\text { Bottom Flanges (hySPAN PROJECT, } \\
\text { Flat-Wise tests) }\end{array}$ & 13.1 & $12.3 \%$ \\
\hline
\end{tabular}

After each servicability and destructive test, the Moisture Content (MC) of the LVL samples were also measured according to AS/NZS 1080.1 [4]. The results show that the $\mathrm{MC}$ values of the connections were around $10 \%$ for all tests with no significant difference among the $\mathrm{MC}$ values 


\subsection{Test set up and loading procedure}

Figure 5 shows the test set up for the push out tests.

Two LVDTs with travelling range of $25 \mathrm{~mm}$ are installed in the front and back of the specimen (Figure 5) to capture the slip between flanges and the web. The adopted loading procedure is according to the European Standard BS EN 26891:1991 [5]. The loading procedure is shown in Figure 6.

As shown in Figure 6, a load was applied up to almost $40 \%$ of the estimated failure load $\left(F_{\text {est }}\right)$ within about two minutes and maintained at this level for about 30 seconds, and then it was reduced to $10 \%$ of the $F_{\text {est }}$ and maintained at this level for about $30 \mathrm{se}-$ conds. Thereafter the load was increased up to failure point of the specimen with the same loading rate as the previous steps. The reason for the load cycle (unloading stage) is to eliminate the internal friction at the interfaces and let the specimen to settle down. The final load-slip response of the push-out test can be idealized as shown in Figure 7.

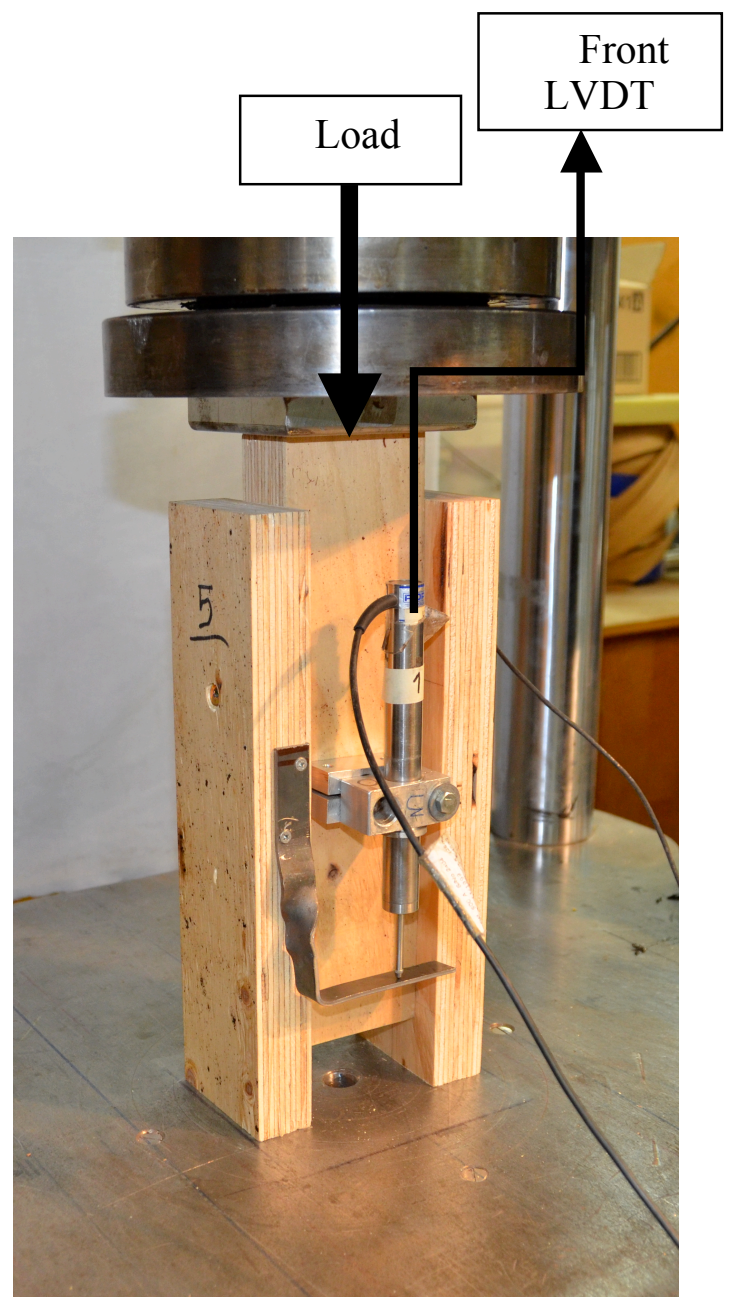

Figure 5. Push out test set up

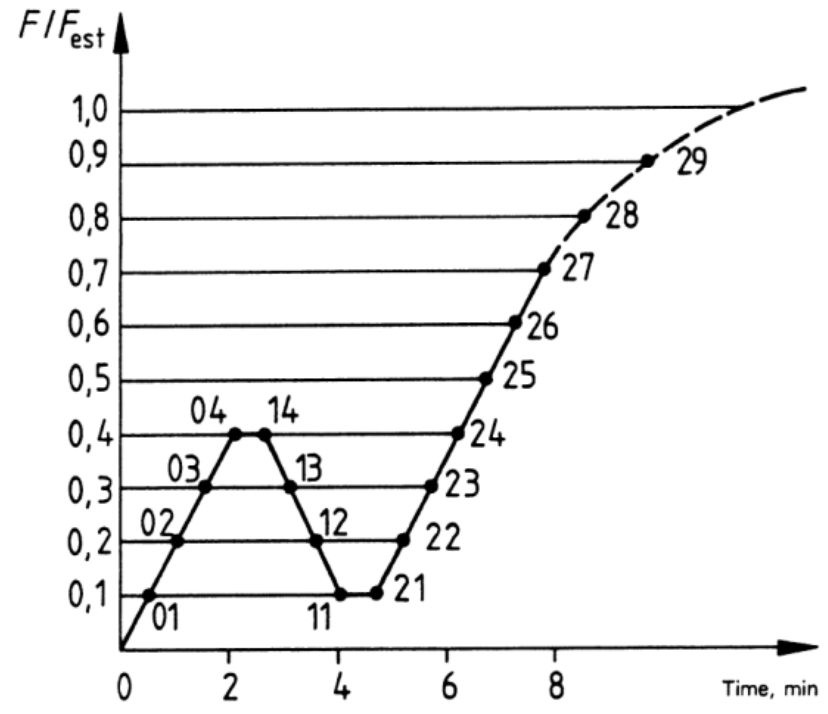

Figure 6. loading procedure based on European Standard

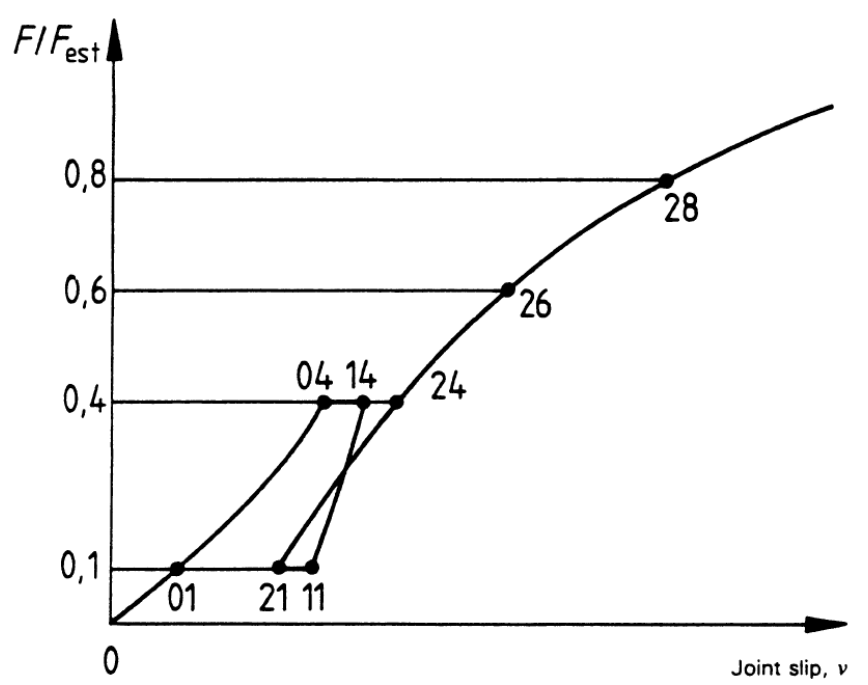

Figure 7. idealized load-slip curves based on European Standard

\subsection{Characteristic behaviour of connections}

The performance of the connections can be assessed by various factors such as strength, stiffness and failure mode in serviceability- and ultimate limit states (SLS \& ULS). The strength of the connection is defined as the maximum load captured during the push-out test before failure happens.

Moreover, the connection stiffness or slip modulus $\left(K_{s}\right)$ is another feature of the connection that can be used to characterise the connection behaviour in SLS and ULS. The slip modulus represents the shear resistance of the connector to the relative displacement of the interfaces. According to BS EN 26891:1991 [3], the slip modulus at different stages 
can be calculated as Equations 1 to 4 . The initial stiffness of the connection $\left(K_{i}\right)$ represents the first slope of the load-slip behaviour, however the slope of the load-slip curve between $10 \%$ and $40 \%$ of the failure load, or the slip modulus $K_{s, 0.4}$, is usually used to identify the serviceability stiffness. Furthermore the slope of the load-slip curve between 10$60 \%$ and $10-80 \%$ of the peak load correspond as the ultimate $\left(K_{s, 0.6)}\right.$ and near collapse $\left(K_{s, 0.8)}\right.$ stiffness of connection, respectively.

$$
\begin{aligned}
& K_{i}=\frac{0.4 F_{e s t}}{v_{04}} \\
& K_{s, 0,4}=\frac{0.4 F_{e s t}}{\frac{4}{3}\left(v_{04}-v_{01}\right)} \\
& K_{0,06}=\frac{0.6 F_{e s t}}{v_{26}-v_{24}+\frac{4}{3}\left(v_{04}-v_{01}\right)} \\
& K_{0,0.8}=\frac{0.8 F_{e s t}}{v_{28}-v_{24}+\frac{4}{3}\left(v_{04}-v_{01}\right)}
\end{aligned}
$$

Where $F_{\text {est }}$ represents the peak-load, $v$ is the relative slip and the subscripts comply with the key points of the diagram shown in Figure 7.

\section{EXPERIMENTAL RESULTS}

Strength and stiffness of the connections

The load-slip results for connection type 1 (with hySPAN Cross-banded as the material of the flanges) and connection type 2 (with and hySPAN PROJECT as the material of the flanges) are shown in Figures 8 and 9, respectively. All the graphs are derived for a single screw by halving the values of the captured load during the push-out test and plotting it versus the slip. As shown in the figures, all of the specimens showed similar bi-linear behaviour, that is, a linear response at the beginning which represents the initial stiffness and then a bit non-linear behaviour after 0.4Fmax. Experimental observation for all the specimens indicates the failure of the screw at the interfaces between the flanges and the web, as well as crushing of the LVL which was caused by bending of the screw in the timber. Since there is a sudden drop in the load at the failure point, yielding of the screws are almost negligible and the ductility of the connection is provided by crushing of LVL around the screw. Table 2 presents the val- ues of the stiffness of the connections. As shown in the table, the average peak-load for connection type 1 and 2 is around $8.5 \mathrm{kN}$ and also there is not much difference between stiffness of connections type 1 and 2. However, due to variable properties of timber (i.e. large value of $\mathrm{CoV}$ for $\mathrm{MOE}$ of $\mathrm{LVL}$ as given in table 1) the values of stiffness of both connection types have a large variation too (high value of $\mathrm{CoV}$ ).For example, while the average value of initial stiffness (Ki) for connection type 1 is $2.12 \mathrm{kN} / \mathrm{mm}$, it has $32 \%$ of variation, which indicates the variable behaviour of timber.

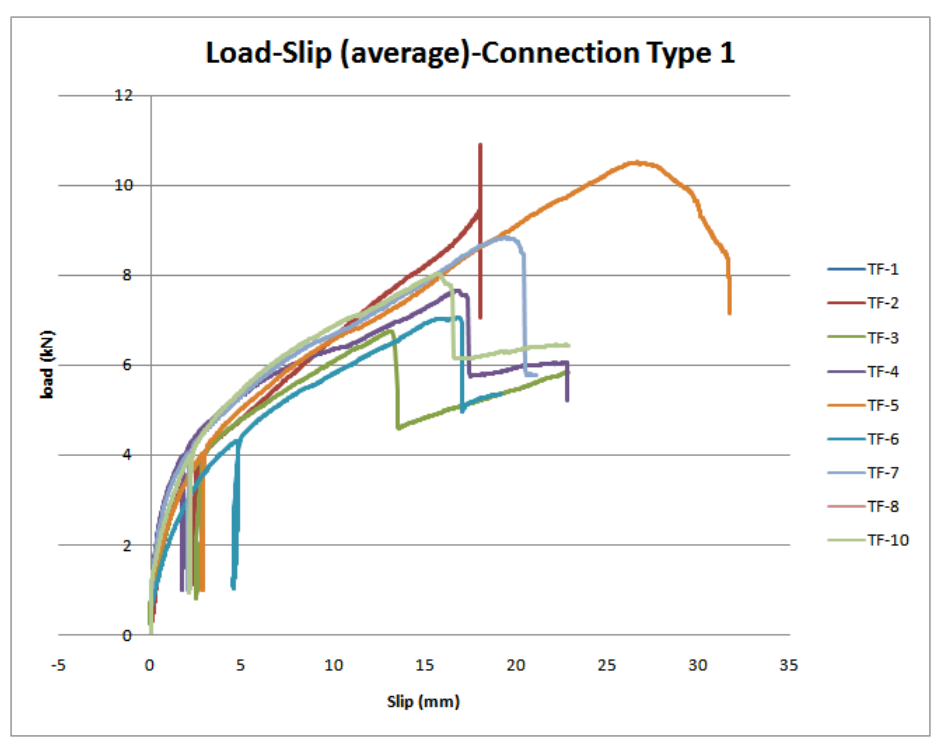

Figure 8 . Response of connection type 1

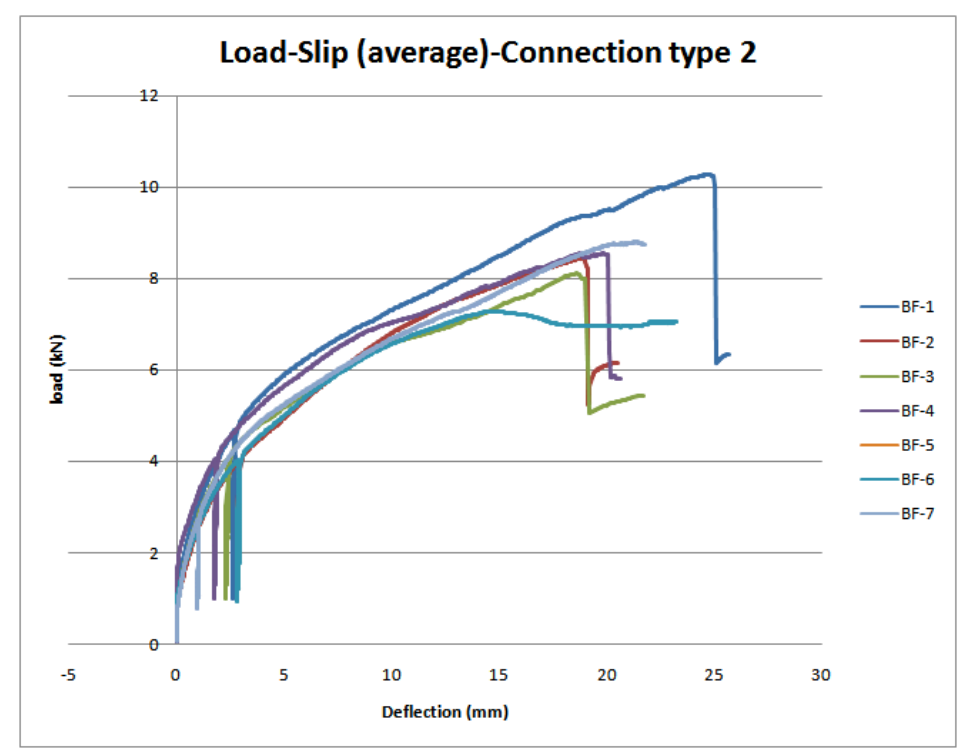

Figure 9. Response of connection type 2

Table 2. Stiffness of the connections 


\begin{tabular}{|l|l|l|l|l|l|}
\hline & $\begin{array}{l}\mathrm{P}_{\max } \\
(\mathrm{kN})\end{array}$ & $\begin{array}{l}\mathrm{K}_{\mathrm{i}} \\
(\mathrm{kN} / \mathrm{mm})\end{array}$ & $\begin{array}{l}\mathrm{K}_{\mathrm{s}, 0.4} \\
(\mathrm{kN} / \mathrm{mm})\end{array}$ & $\begin{array}{l}\mathrm{K}_{\mathrm{s}, 0.6} \\
(\mathrm{kN} / \mathrm{mm})\end{array}$ & $\begin{array}{l}\mathrm{K}_{\mathrm{s}, 0.8} \\
(\mathrm{kN} / \mathrm{mm})\end{array}$ \\
\hline TF & & & & & \\
\hline AVE & 8.45 & 2.12 & 1.64 & 1.25 & 0.68 \\
\hline CoV & $14 \%$ & $32 \%$ & $32 \%$ & $39 \%$ & $17 \%$ \\
\hline BF & & & & & \\
\hline AVE & 8.46 & 2.32 & 1.78 & 1.24 & 0.71 \\
\hline Cov & $11 \%$ & $17 \%$ & $17 \%$ & $21 \%$ & $17 \%$ \\
\hline
\end{tabular}

Figure 10. Response of connection type 1 without the load cycle (with eliminating the unloading stage)

\subsection{Analytical Model for shear-Slip behaviour of the connections}

An analytical model for each type of connection (i.e. type 1 and 2) can be developed using the load-slip response of the connections. In this regards, a nonlinear regression is applied to all of the curves obtained from the push-out tests, and the best mathematical expressions of the load-slip behaviour of connections was derived.

Figures 10 and 11 show the load-slip responses obtained from push-out tests where the load cycle is eliminated from all of the curves. Moreover, three additional sample of each connection type (1 and 2) were tested without the load cycle (i.e. the load was constantly increased until the failure happens) which are also presented in the Figures 9 and 10 (TF$11 \& 12$ and 14 and BF-8 \& 9 and10). The graphs show that there is no significant difference in loadslipe response of the connections as a result of two different loading procedures (with and without load cycle).

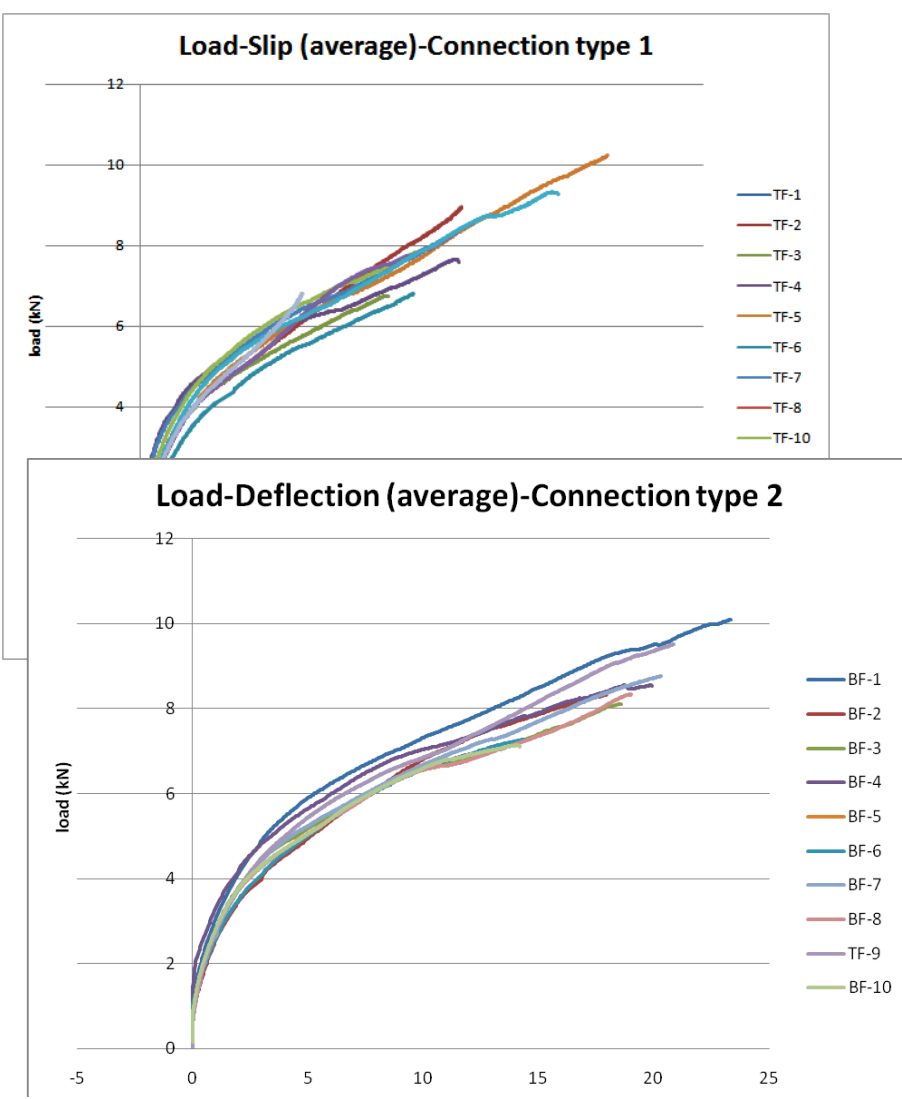

Figure 11. Response of connection type 2 without the load cycle (with eliminating the unloading stage)

According to Figures 10 and 11, the load-slip response of connections can be divided into two stages. The first stage of the response starts with a sharp increase in the load level which represents the initial stiffness, $K_{0}$, of the connection. The second stage of behaviour is followed by strain-hardening part with the stiffness, $K_{\mathrm{p}}$, which is associated with a gradual increase in the load level and a large slip. After that, the failure occurs in the connection with a sudden drop in the load which occurs immediately after the fracture of the screws.

Richard-Abbott model [6] with four unknown parameters can be employed to represent the behaviour of connections. The Richard-Abbott model was originally proposed for semi-rigid steel connections, and for timber connections with normal screws it can be expressed as Equation 5:

$$
P=\frac{\left(K_{0}-K_{p}\right) v}{\left[1+\left(\frac{\left(K_{0}-K_{p}\right) v}{P_{0}}\right)^{n}\right]^{1 / n}}+K_{p} v
$$

Where $K_{0}$ is the initial stiffness, $K_{p}$ is the strainhardening stiffness, $P_{0}$ is a reference shear force and $n$ is a parameter which associates to the sharpness of the curve. Table 3 presents the values for $\mathrm{K}_{0}, \mathrm{~K}_{\mathrm{P}}, \mathrm{P}_{0}$ and $\mathrm{n}$ for connection type 1 and 2 . Values of $\mathrm{R}^{2}$ represent the accuracy of the regression curve. If $\mathrm{R}^{2}$ is equal to 1, all of the data are $100 \%$ correlated. Moreover, since the behaviour of connection type 1 and 2 are similar (See figures 10, 11 and 12) the constant values were calculated considering all of the specimens, and Figure 12 shows the load-slip response including all of the specimens as well as the regression curve (the bold black curve).

Table 2. Constant values of the analytical model

\begin{tabular}{|l|l|l|l|l|l|}
\hline & $\mathrm{K}_{0}$ & $\mathrm{~K}_{\mathrm{P}}$ & $\mathrm{P}_{0}$ & $\mathrm{n}$ & $\mathrm{R}^{2}$ \\
\hline Type 1 & 6.029 & 0.2418 & 4.367 & 1 & 0.98 \\
\hline Type 2 & 5.482 & 0.1859 & 5.27 & 1 & 0.97 \\
\hline All of the & $\mathbf{5 . 6 4 7}$ & $\mathbf{0 . 2 1 2 5}$ & $\mathbf{4 . 8 2 2}$ & $\mathbf{1}$ & $\mathbf{0 . 9 7}$ \\
\hline
\end{tabular}




\section{Specimens}

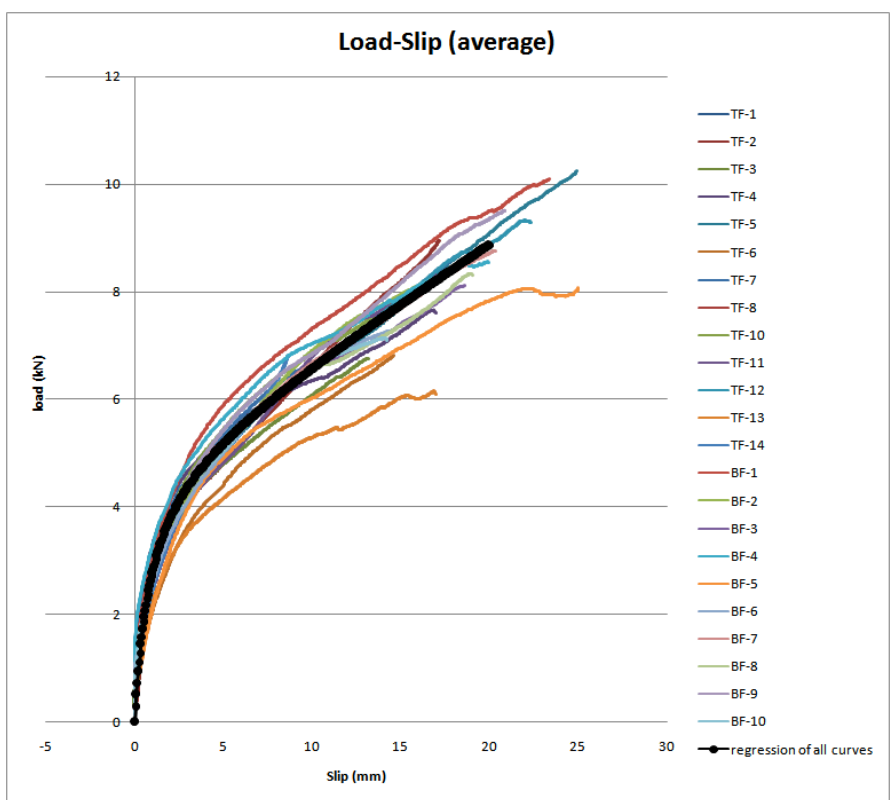

Figure 12. Response of connections without the load cycle (with eliminating the unloading stage)

Therefore, with substituting the values of $\mathrm{K}_{0}, \mathrm{~K}_{\mathrm{P}}, \mathrm{P}_{0}$ and $\mathrm{n}$ in Equation 5, the mathematical expression of the behaviour of the timber connection with normal screws will be as follows:

$$
P=\frac{(5.4345) v}{[1+(1.127 v)]}+0.2125 v
$$

Where $\mathrm{P}$ and $v$ represent the shear force and the slip, respectively. Equation 6 can adequately express the first and second stages of the behaviour for timber connections with normal screws which can be easily incorporated into nonlinear FE analyses of timber beams with normal screws.

\section{CONCLUSION}

Based on the push-out tests conducted on timber connections, the following conclusions can be made: the maximum peak-load of connections type 1 and 2 were near identical, and it shows that failure of the screws governs the failure of the connection and it is almost independent of the different type of LVL in the connections. The values of the stiffness in connection type 1 and 2 are also similar which confirms again, that the behaviour of the connection was almost independent of the type of LVL used for flanges. However, due to variable properties of timber, the values of stiffness for timber connection have a large variation too. Moreover, timber connection with normal screws displayed a brittle behaviour with a sudden drop at the failure point. Finally, the behaviour of timber connection with normal screws can be expressed with a mathematical equation (Equation 6) which can be incorporated into nonlinear FE analyses of timber beams.

\section{REFRENCES}

[1] K.Bayne , S.Taylor. Attitude to the use of wood as a structural material in non-residential applications: opportunities for growth, Forest \& Wood Products Research \& Development Corporation, 2006

[2] AS 1649-2001, Methods of test for mechanical fasteners and connector- Basic working loads and characteristic strength

[3] AS/NZS 4063.1:2010: Characterization of structural timber - Test methods

[4] AS/NZS 1080.1: Timber-methods of test, Moisture content, (1):40, 1997.

[5] BS EN2689:1991 Timber Structures-Joints made with mechanical fasteners-general principle for the determination of strength and deformation characteristics

[6] Chan, S.L. and P.P.T.Chui, Non-linear static and cyclic analysis of steel frames with semi regid connection. First ed2000, Killington, oxford: Elsevier.336. 